\title{
Inducible-Clindamycin Resistance in Staphylococcus aureus Isolates in Rivers State, Nigeria
}

\author{
Easter Godwin Nwokah*, Samuel Douglas Abbey \\ Department of Medical Laboratory Science, Rivers State University of Science and Technology, Port Harcourt, Nigeria \\ Email address: \\ easternwokah@yahoo.com (E. G. Nwokah) \\ ${ }^{*}$ Corresponding author
}

To cite this article:

Easter Godwin Nwokah, Samuel Douglas Abbey. Inducible-Clindamycin Resistance in Staphylococcus aureus Isolates in Rivers State, Nigeria. American Journal of Clinical and Experimental Medicine. Vol. 4, No. 3, 2016, pp. 50-55. doi: 10.11648/j.ajcem.20160403.13

Received: March 20, 2016; Accepted: March 30, 2016; Published: May 11, 2016

\begin{abstract}
Clindamycin is indicated in the treatment of skin and soft-tissue infections caused by Staphylococcal species. Treatment of an infection caused by a strain carrying inducible erm gene using clindamycin or any non-inducer macrolide can lead to clinical failure. The present study was aimed to detect inducible-clindamycin resistance $\left(\mathrm{MLS}_{\mathrm{Bi}}\right)$ among $S$. aureus isolates in Port Harcourt, Nigeriaand to study the relationship between clindamycin and methicillin-resistant $S$. aureus (MRSA).Two hundred and five (205) non-duplicate Staphylococcus aureus previously isolated from human sources were randomly collected from three health facilities- University of Port Harcourt Teaching Hospital, Braithwaite Memorial Specialist Hospital and De-Integrated Laboratories-all located in Port Harcourt, Nigeria, for this study from August, 2012 to July, 2013. Isolates were grouped as hospital in-patient (termed hospital- acquired - Nosocomial; $n=76$ ) and out- patient cases (community-acquired; $\mathrm{n}=129$ ) Staphylococcus aureus. The isolates collected were reconfirmed following standard laboratory protocols. All confirmed isolates were stored in glycerol at $+4^{\circ} \mathrm{C}$ (later sub-cultured for various phenotypic analyses). Using the disk diffusion method, detection of MRSA was carried out with $1 \mu \mathrm{g}$ of oxacillin (OXOID) placed on Mueller-Hinton agar with $4 \% \mathrm{NaCl}$ supplementation).Antimicrobial susceptibility testing was performed using Erythromycin $(15 \mu \mathrm{g})$ and Clindamycin $(2 \mu \mathrm{g})$ both obtained from OXOID, UK. All clindamycin-sensitive isolates that were also erythromycin-resistant were subjected to D-Test phenotype (Inducible-clindamycin resistance). Among the 205 S. aureus isolates studied, Forty-four $(21.5 \%)$ showed resistance to erythromycin, while 38 of these erythromycin-resistant isolates were simultaneously sensitive to clindamycin. Overall, out of 205 isolates, inducible-clindamycin resistance was detected in 23 (11.2\%) of the isolates. These 23 (inducible $\mathrm{MLS}_{\mathrm{B}}$ phenotype) are among 38 erythromycin-resistant $S$. aureus that were simultaneously sensitive (phenotypically) to clindamycin. Ten (4.9\%) of the total (205) study isolates expressed constitutive resistance to clindamycin. Oxacillin Resistance (MRSA) was detected in 25 (12.2\%) of the 205 isolates. Among the 38 erythromycin-resistant S. aureus, four were MRSA while $3(75 \%)$ of the 4 erythromycin-resistant MRSA expressed inducible resistance to clindamycin. 20 $(58.8 \%)$ of 34 erythromycin-resistant MSSA expressed inducible resistance to clindamycin. MRSA phenotype was not significantly correlated $(\mathrm{p}=0.9430)$ to inducible-clindamycin resistance. Inducible clindamycin-resistance often leads to treatment failure. The clinical microbiology laboratories in Nigeria should consider routine testing and reporting of inducible clindamycin resistance in $S$. aureus. There is also the need for sustained surveillance of antimicrobial susceptibilities of $S$. aureus in this region.
\end{abstract}

Keywords: Staphylococcus aureus, MRSA, Erythromycin- Resistance, Inducible-Clindamycin Resistance

\section{Introduction}

The determination of antimicrobial susceptibility pattern of a clinical isolate is very important for the effective management of infected patients. This is moreso in the light of the emergence of multidrug-resistant microorganisms. Staphylococcus aureus has the notoriety of being one of the most common organisms causing both hospital and community-acquired infections in many regions of the world. The increasing prevalence of methicillin resistance among Staphylococci is an increasing problem [1-4]. In view of the 
gradual depletion in the armamentarium of antimicrobial agents effective against $S$. aureus, there has been renewed interest in the use of the Macrolide(erythromycin, clarithromycin)-Lincosamide (clindamycin, lincomycin)Streptogramin B (quinupristin-dalfopristin) $\left(\mathrm{MLS}_{\mathrm{B}}\right)$ antibiotics to treat $S$. aureus infections with clindamycin being the preferred agent due to its excellent pharmacokinetic properties [5-6]. MLS $_{\mathrm{B}}$ antibiotics although structurally related, exhibit similar mode of action. They inhibit bacterial protein synthesis by binding to $23 \mathrm{~s}$ rRNA, which is a part of large ribosomal subunit.

Resistance to macrolides (e.g. erythromycin) can occur by two different mechanisms: the efflux mechanism encoded by the gene- macrolide streptogramin resistance $(m s r A)$ and ribosome alteration or modificationmechanism due to erythromycin ribosome methylase (ermgene) [7-8].

Target modification alters a site in $23 \mathrm{~S}$ rRNA common to the binding of $\mathrm{MLS}_{\mathrm{B}}$ antibiotics. Modification of the ribosomal target confers cross-resistance to $\mathrm{MLS}_{\mathrm{B}}$ antibiotics. This cross-resistance, called the MLS-B phenotype, results from enzymatic methylation of an adenine residue of the $23 \mathrm{~S}$ component of the $50 \mathrm{~S}$ ribosomal subunit that these 3 drug groups bind to [9].

Expression of resistance to $\mathrm{MLS}_{\mathrm{B}}$ in staphylococci may be constitutive $\left(\mathrm{MLS}_{\mathrm{Bc}}\right)$ or inducible $\left(\mathrm{MLS}_{\mathrm{Bi}}\right)$. In constitutive resistance, r-RNA methylase is always produced $\left(\mathrm{MLS}_{\mathrm{Bc}}\right)$; whereas in inducible, methylase is produced only in the presence of an inducing agent $\left(\mathrm{MLS}_{\mathrm{Bi}}\right)$ [10]. In vitro, $S$. aureus isolates with constitutive resistance are resistant to both erythromycin and clindamycin whereas those with inducible resistance are resistant to erythromycin and appear sensitive to clindamycin $\left(\mathrm{MLS}_{\mathrm{Bi}}\right)$ [11].

For $\mathrm{MLS}_{\mathrm{Bi}}$ strains, erythromycin will induce production of the methylase, which allows clindamycin resistance to be expressed. Inducible clindamycin resistance can then be detected with a simple disk approximation test, commonly referred as the D test [12]. When $15 \mu \mathrm{g}$ erythromycin (E) or 2 $\mu \mathrm{g}$ clindamycin $(\mathrm{C})$ are placed 15 to $20 \mathrm{~mm}$ apart on an agar plate that has been inoculated with the clinical isolate, the lack of a zone of inhibition around the erythromycin disc indicates bacterial resistance to macrolides (e.g. perhaps due to expression of a P-glycoprotein efflux pump that affects macrolides). The large clear zone of inhibition around the clindamycin disc indicates sensitivity to clindamycin. For a positive D-test, diffusion of erythromycin from the disc towards the clindamycin disc does not kill bacteria due to $S$. aureus resistance to macrolides. However, the bacterial isolate contains a strain of $S$. aureus with an erythromycininducible methylase $\left(\mathrm{MLS}_{\mathrm{Bi}}\right)$ that is encoded by a plasmidborne gene $(\mathrm{erm})$. When this methylase is induced it alters the binding site on the $23 \mathrm{~S}$ subunit of the $50 \mathrm{~S}$ ribosome that both erythromycin and clindamycin bind to, making both antibiotics ineffective (inducing resistance). As a result, as erythromycin diffuses outward towards clindamycin, resistance to clindamycin is induced prior to its diffusion from the neighboring disk. In contrast, growth-inhibiting concentrations of clindamycin reach the zone near erythromycin before erythromycin can arrive to induce resistance (due to the shorter distance for diffusion), resulting in inhibited growth. The inhibition of bacterial growth produces a "D" shape surrounding the clindamycin disk, which is considered a "positive" D-test. [9].

The treatment of patients harboring MLS $_{\mathrm{Bi}}$ staphylococci with clindamycin leads to the development of constitutive resistance, subsequently leading to therapeutic failure [13]. In case of another mechanism of resistance mediated through msrA genes i.e. efflux of antibiotic, Staphylococcal isolates appear erythromycin-resistant and clindamycin-sensitive both in vivo and in vitro and the strain do not typically become clindamycin resistant during therapy [6].

The present study was aimed to detect inducible clindamycin resistance $\left(\mathrm{MLS}_{\mathrm{Bi}}\right)$ among $S$. aureus isolates in our geographical setting and to study the relationship between clindamycin and methicillin-resistant $S$. aureus (MRSA).

\section{Materials and Methods}

\subsection{Study Area and Collection of Specimens}

Two hundred and five (205) clinical isolates of Staphylococcus aureus, were collected between August, 2012 and July, 2013, from three health facilities- University of Port Harcourt Teaching Hospital, Braithwaite Memorial Specialist Hospital and De-Integrated Laboratories-all located in Port Harcourt, Rivers State of Nigeria, were used in this study. Isolates were previously cultivated from different specimens such as Urine, Blood, High Virginal Swab, Endo-cervical Swab, Intra- cervical Swab, Wound swab, Ear Swab, Eye Swab, Semen and other body fluids. Isolates were also grouped as Hospital in-patient or Out-patient isolates according to the criteria as prescribed by the Centers for Disease Control and Prevention [14].Reconfirmation of isolates were done using colonial morphology on DNase agar plate, Mannitol salt agar plate, Gram stain, Catalase and Coagulase (bound / free) tests following standard protocols [15].

All confirmed isolates were stored at $+4^{\circ} \mathrm{Cand}$ later sub cultured to carry out antibiotic susceptibility testing against Oxacillin $(1 \mu \mathrm{g})$ (MRSA) and D-Test (Inducible clindamycin resistance) using Erythromycin $(15 \mu \mathrm{g})$ and Clindamycin $(2 \mu \mathrm{g})$.

\subsection{Detection of MRSA}

Disk diffusion tests as per the method described by Kirby and Bauer (1966) [16]were performed with $1 \mu \mathrm{g}$ of oxacillin (OXOID, UK) per disk placed on Mueller-Hinton agar(OXOID, UK) with $4 \% \mathrm{NaCl}$ supplementation. The zone of inhibition was determined after 24 hours of incubation at $37^{\circ} \mathrm{C}$. Organisms showing inhibition zones equal to or less than $10 \mathrm{~mm}$ were interpreted as resistant to oxacillin. Organisms with a zone equal to or greater than $12 \mathrm{~mm}$ were interpreted as susceptible while those with an inhibition zone of 11-12 mm were interpreted as intermediate. S. aureus strain ATCC 25923 was used as control. 


\subsection{Test for Macrolide Induction (D-Test)}

Test was performed on all isolates of Staphylococcus aureus on Muller-Hinton agar (MH), using 2-hour-old nutrient broth culture. Briefly, inocula of bacteria were prepared to $0.5 \mathrm{McF}$ arland standards. Sterile swab stick was dipped into the bacteria suspension and used to streak the MH agar. After seeding the agar plate with $S$. aureus, erythromycin $(15 \mu \mathrm{g})$ and clindamycin $(2 \mu \mathrm{g})$ disks, all obtained from Oxoid, UK, were placed 15-20 mm apart for the detection of inducible resistance of clindamycin by erythromycin (D-test) as previously described [12]. Plates were incubated at $37^{\circ} \mathrm{C}$ for $24 \mathrm{hrs}$. Inducible MLSB phenotype $\left(\mathrm{MLS}_{\mathrm{Bi}}\right) \mathrm{S}$. aureus isolates were interpreted as isolates which showed resistance to erythromycin (zone size $\leq 13 \mathrm{~mm}$ ) while being sensitive to clindamycin (zone size $\geq 21$ $\mathrm{mm}$ ) and giving $\mathrm{D}$ shaped zone of inhibition around clindamycin with flattening towards erythromycin disc (D test positive). Detection of a flattened zone correlates with presence of the erm gene and resistance to clindamycin even though it may appear susceptible to clindamycin by routine testing methods. S. aureus isolates which showed resistance to both erythromycin (zone size $\leq 13 \mathrm{~mm}$ ) and clindamycin (zone size $\leq 14 \mathrm{~mm}$ ) with circular shape zone of inhibition around clindamycin were interpreted as Constitutive $\mathrm{MLS}_{\mathrm{B}}$ phenotype $\left(\mathrm{MLS}_{\mathrm{BC}}\right)$.

\subsection{Data Analysis}

All data were analyzed using the Chi square and t-tests. In addition, SPSS version 17.0 statistical package was employed. P-values of $<0.05$ were accepted as significant.

\section{Results}

Table 1.Prevalence of MRSA among S. aureus isolates in Port Harcourt.

\begin{tabular}{llll}
\hline Category & Number screened & MRSA (\%) & MSSA (\%) \\
\hline Total no of $S$. & 205 & $25(12.2)$ & $180(87.8)$ \\
aureus screened & 129 & $7(5.4)$ & $122(94.6)$ \\
Out- patient & 76 & $18(23.7)$ & $58(76.3)$ \\
In-patient & & 0.000318 & 0.179371 \\
p-value & & \\
\hline
\end{tabular}

Two hundred and five (205) non-duplicate isolates of Staphylococcus aureus cultivated from different clinicalspecimens between August, 2012 and July, 2013, were used in this study. The oxacillin disc susceptibility testing showed that $25(12.2 \%)$ out of 205 isolates of S. aureus were resistant to oxacillin (Table 1).

Forty-four (36 MSSA and 8 MRSA) of the isolates showed resistance to erythromycin (Table 2).

Table 2. Antimicrobial Resistance Profile of S. aureus isolates Number (\%) of Isolates resistant among.

\begin{tabular}{llll}
\hline Antimicrobial Agent & $\begin{array}{l}\text { MSSA } \\
(\mathbf{n = 1 8 0})\end{array}$ & $\begin{array}{l}\text { MRSA } \\
(\mathbf{n = 2 5})\end{array}$ & $\begin{array}{l}\text { Total } \\
(\mathbf{n = 2 0 5})\end{array}$ \\
\hline Erythromycin $(15 \mu \mathrm{g})$ & $36(20)$ & $8(32)$ & $44(21.5)$ \\
Clindamycin $(2 \mu \mathrm{g})$ & $4(2.2)$ & $6(24)$ & $10(4.9)$ \\
\hline
\end{tabular}

$\mathrm{P}<0.05$

Table 3 shows the occurrence of constitutive clindamycin resistance among $S$. aureus isolates. Ten (4 MSSA and 6 MRSA) of the total (205) study isolates expressed constitutive resistance to clindamycin.

Table 3. Occurrence of Constitutive Clindamycin Resistance among S. aureus.

\begin{tabular}{lllll}
\hline $\begin{array}{l}\text { Population } \\
\text { screened }\end{array}$ & $\begin{array}{l}\text { No. } \\
\text { screened }\end{array}$ & $\begin{array}{l}\text { No. positive } \\
(\%)\end{array}$ & $\begin{array}{l}\text { No. negative } \\
(\%)\end{array}$ & $\begin{array}{l}\text { P- } \\
\text { value }\end{array}$ \\
\hline S. aureus & 205 & $10(4.9)$ & $195(95.1)$ & \\
MRSA & 25 & $6(24.0)$ & $19(76.0)$ & $<0.05$ \\
MSSA & 180 & $4(4.0)$ & $176(96.0)$ & \\
In-patient & 76 & $6(7.9)$ & $70(92.1)$ & $<0.05$ \\
Out-patient & 129 & $4(3.1)$ & $125(96.9)$ & \\
\hline
\end{tabular}

Table 4 shows inducible clindamycin resistance. Overall, $23(11.2 \%)$ of the isolates, expressed inducible resistance. Furthermore, out of 38 erythromycin-resistant $S$. aureus that were simultaneously sensitive (phenotypically) to clindamycin in this study, $23(60.5 \%)$ expressed inducible resistance to clindamycin (inducible $\mathrm{MLS}_{\mathrm{B}}$ phenotype) (Table 4; Figure 1). There was no significant difference in $\operatorname{MLS}_{\mathrm{B}}$ detection rate between Erythromycin- resistant MRSA and Erythromycin- resistant MSSA $(p=0.9430)$. Similarly, there was no significant difference in $\mathrm{MLS}_{\mathrm{B}}$ detection rate between the corresponding in-patient and out-patient isolates $(\mathrm{p}=$ 0.3532).

Table 4. Occurrence of Inducible Clindamycin Resistance among S. aureus isolates.

\begin{tabular}{lllll}
\hline & No screened & No. of positive (\%) & No. of Negative (\%) & P-value \\
\hline $\begin{array}{l}\text { S.aureus } \\
\text { ERSA/CSSA }\end{array}$ & 205 & $23(11.2)$ & $182(88.8)$ & \\
Total population & 38 & $23(60.5)$ & $15(39.5)$ & \\
MRSA & 4 & $3(75.0)$ & $1(25.0)$ & 0.942952976 \\
MSSA & 34 & $20(58.8)$ & $14(41.2)$ & 0.353237822 \\
In-patient & 17 & $13(76.5)$ & $4(23.5)$ & $11(52.4)$ \\
Out-patient & 21 & $10(47.6)$ & & \\
\hline
\end{tabular}

ERSA $=$ Erythromycin Resistant $S$. aureus

CSSA $=$ Clindaycin Sensitive $S$. aureus 


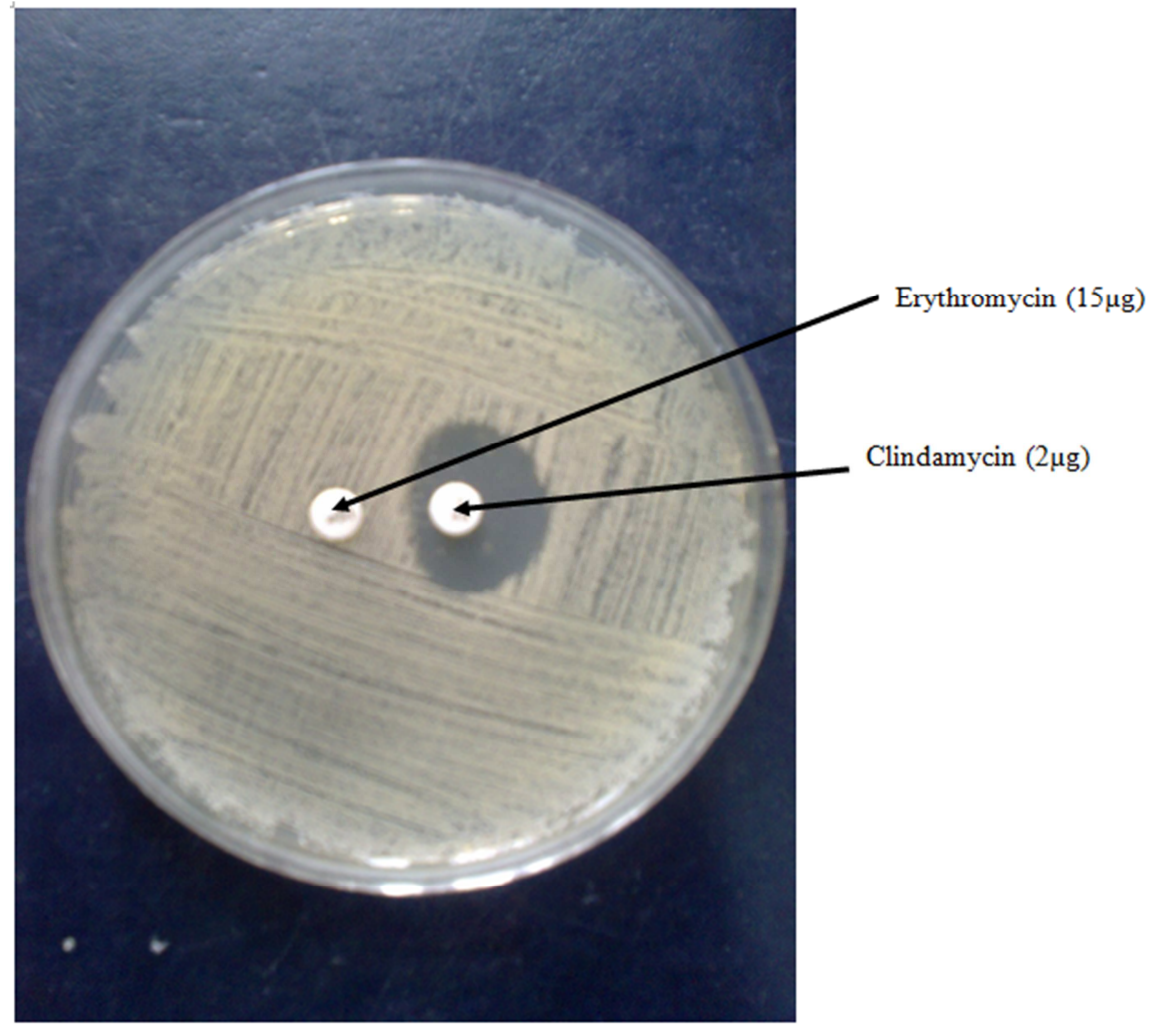

Figure 1. Inducible Clindamycin Resistance in S. aureus.

\section{Discussion}

Clindamycin is indicated in the treatment of skin and softtissue infections, caused by staphylococcal species. It is also used as an alternative for patients who are allergic to penicillin [11]. Treatment of an infection caused by a strain carrying inducible erm gene using clindamycin or any noninducer macrolide can lead to clinical failure [11]. In vitro routine tests for clindamycin susceptibility may fail to detect inducible clindamycin resistance due to erm genes resulting in treatment failure, thus necessitating the need to detect such resistance by a simple $\mathrm{D}$ test on a routine basis.

Among the $205 \mathrm{~S}$. aureus isolates studied, Forty-four $(21.5 \%)$ showed resistance to erythromycin (Table 2). This is higher than those reported by Ajantha et al., 2008 [17] (15.7\%) but lower than $28.4 \%$ [18] and $32.4 \%$ [6]. Erythromycin is one of the commonest and affordable antimicrobial agents available locally in Nigeria. An erythromycin- resistance rate of $21.5 \%$ in this study is actually a cause for concern. Out of 38 erythromycinresistant $S$. aureus that were simultaneously sensitive (phenotypically) to clindamycin in this study, 23 (60.5\%) expressed inducible resistance to clindamycin (inducible $\mathrm{MLS}_{\mathrm{B}}$ phenotype) (Table 4). Overall, out of 205 isolates, inducible clindamycin resistance was observedin 23 (11.2\%) of the isolates (Table 4). When compared to this study, higher rates of inducible clindamycin resistance had been reported: $50.6 \%$ [19] and 49\% [17] as well as lower rate - $10.5 \%$ [18].

Ten (4 MSSA and 6 MRSA) of the total (205) study isolates expressed constitutive resistance to clindamycin
(Table 3). Furthermore, 3 (75\%) of the four erythromycinresistant MRSA expressed inducible resistance to clindamycin, while 20 (58.8\%) of 34 erythromycin-resistant MSSA also expressed inducible resistance to clindamycin (Table 4).

Shittu et al., (2012) [2] had reported 2 of 5 erythromycinresistant MRSA as expressing inducible resistance to clindamycin in a study while in another related study in KwaZulu-Natal province, South Africa, all the 50 erythromycin-resistant MRSA were positive for inducible $\mathrm{MLS}_{\mathrm{B}}$ resistance using the D-test method [20]

A survey in Pennsylvania, USA, observed that $68 \%$ of MSSA and $12.3 \%$ of MRSA were D-test positive [21]. Observations indicate that the incidence of constitutive and inducible $\mathrm{MLS}_{\mathrm{B}}$ resistance in staphylococcal isolates varies by geographic region [1].

It becomes more worrisome when 23 out of 38 erythromycin-resistant $S$. aureus, as indicated in this study, are inducibly resistant to clindamycin. There appears to be paucity of literatures on $S$. aureus resistance to clindamycin in this locality probably due to oversight or complete ignorance. The D-test is a simple and reliable method to detect inducible resistance to clindamycin and has been so recommended by the National Committee for Clinical Laboratory Standards [22] as well as other investigators [2324]. Reporting $S$. aureus as susceptible to clindamycin without verifying the inducible-clindamycin resistance status may result in institution of inappropriate clindamycin therapy and the consequent treatment failure. The clinical microbiology laboratories in Nigeria should therefore 
consider routine testing and reporting of inducible clindamycin resistance in $S$. aureus. The proportion of MRSA with the inducible $\mathrm{MLS}_{\mathrm{B}}$ phenotype (3 of 4 tested) (Table 4) indicates that clindamycin may not be a therapeutic option for the treatment of an infection attributed to an inducibly resistant MRSA. If clindamycin is used for treatment of infections with $\mathrm{MLS}_{\mathrm{B}}$-positive isolates, close follow-up and monitoring of failure or relapse is needed. However, in more severe infections, the presence of the $M_{L} S_{B}$ phenotype should preclude the use of clindamycin.

\section{Conclusion}

Inducible clindamycin-resistance often leads to treatment failure and therefore the detection rate in this study is instructive for clinical microbiology laboratories in Nigeria to consider routine testing and reporting of inducible clindamycin resistance in $S$. aureus. There is also the need for sustained surveillance of antimicrobial susceptibilities of $S$. aureus in this region.

\section{References}

[1] Shittu, A. O., Lin, J. and Kolawole, D. O. (2006). Antimicrobial susceptibility patterns of Staphylococcus aureus and characterization of MRSA in Southwestern Nigeria. Wounds, 18, 77-84.

[2] Shittu, A., Oyedara, O., Abegunrin, F. Okon, K. Raji, A. Taiwo, S. Ogunsola, F., Onyedibe, K. and Elisha, G. (2012). Characterization of methicillin-susceptible and -resistant staphylococci in the clinical setting: a multicentre study in Nigeria. Biomed Central Infectious Diseases, 12, 286-295.

[3] Nwokah, E. G. Obunge, O. K, Ayodele, M. B. O., Abbey, S. D. and Tatfeng, Y. M. (2012). Nasal Carriage of Staphylococcus aureus and MRSA among Food Handlers in a Sub-Urban Setting in Rivers State, Nigeria. Nigerian Biomedical Science Journal, 8 (3), 58-61.

[4] Okwu, M. U., Okorie, T. G., Mitsan, O. and Osakue, E. O. (2014). Prevalence and comparison of three methods for detection of methicillin-resistant Staphylococcus aureus (MRSA) isolates in tertiary health institutions in Nigeria. Canadian Open Biological Sciences Journal, 1 (1), 1-12.

[5] Delialioglu N, Aslan G, Ozturk C, Baki V, Sen S, and Emekdas G. (2005). Inducible clindamycin resistance in staphylococci isolated from clinical samples. Japan Journal ofInfectious Disease, 58, 104-106.

[6] Deotale V, Mendiratta DK, Raut U, and Narang P (2010). Inducible clindamycin resistance in Staphylococcus aureusisolated from clinical samples. Indian Journal Medical Microbiology, 28,124-126.

[7] Leclercq R., R. B. Giannattasio, H. J. Jin, and B. Weisblum (1991). Bacterial resistance to macrolide, lincosamide and streptogramin antibiotics by target modification. Antimicrobial Agents Chemotherapy, 35,1267-1272.

[8] Weisblum B (1999) Resistance to macrolide-lincosamidestreptogramin antibiotics, p. 682-98. In: V. A. Fischetti (ed.), Gram-positive pathogens. American Society for Microbiology,
Washington, D. C.

[9] Woods, C. R (2009). Macrolide-inducible resistance to clindamycin and the D-test. Pediatric Infectious Diseases Journal, 28, 1115-1118.

[10] Leclercq R. (2002). Mechanisms of resistance to macrolides and lincosamides: Nature of the resistance elements and their clinical implications. Clinical Infectious Diseases, 34, 482492.

[11] Drinkovic D, Fuller ER, Shore KP, Holland DJ, and EllisPegler R (2001) Clindamycin treatment of Staphylococcus aureus expressing inducible clindamycin resistance. Journal of Antimicrobial Chemotherapy, 48, 315-316.

[12] Fiebelkorn K. R., Crawford S. A., McElmeel M. L., and Jorgensen J. H (2003). Practical disk diffusion method for detection of inducible clindamycin resistance in Staphylococcus aureus and coagulasenegative staphylococci. Journal Clinical of Microbiology; 41, 4740-4744.

[13] Siberry GK, Tekle T, Carroll K, and Dick J (2003). Failure of clindamycin treatment of methicillin-resistant Staphylococcus aureus expressing inducible clindamycin resistance in vitro. Clinical Infectious Diseases,37, 1257-1260.

[14] Garner, J. S., Jarvis, W. R., Emori, T. G., Horan T. C. and Hughes, J. M. (1988). CDC definitions for nosocomial infections. American Journal of Infection Control, 16, 128140 .

[15] Cheesbrough, M. (2000). District laboratory practice in tropical countries (2), Cambridge University press, UK.

[16] Bauer, A. W., Kriby, W. M., Sherris, W. M. and Turk, J. C. (1966). Bauer-Kirbystandardized, single disc susceptibility, test for rapid growing pathogens. AmericanJournal of ClinicalPathology, 45, 493-498.

[17] Ajantha GS, Kulkarni RD, Shetty J, Shubhada C, and Jain P. (2008). Phenotypic detection of inducible clindamycin resistance among Staphylococcus aureus isolates by using the lower limit of recommended inter-disk distance. Indian Journal of Pathology Microbiology, 51, 376-378.

[18] Prabhu K, Rao S, and Rao V. (2011). Inducible clindamycin resistance in Staphylococcus aureus isolated from clinical samples. Journal of Laboratory Physicians, 3, 25-27.

[19] Goyal R, Singh NP, Manchanda V, Mathur M. (2004). Detection of clindamycin susceptibility in macrolide resistant phenotypes of Staphylococcus aureus. Indian Journal Medical Microbiology, 22, 251-254.

[20] Shittu, A. O. and Lin, J. (2006). Antimicrobial susceptibility patterns and characterization of clinical isolates of Staphylococcus aureus in KwaZulu-Natal province, South Africa. BioMed Central Journal of Infectious Disease, 6(1), 125-137.

[21] Levin, T. P., Suh, B., Axelrod, P., Truant, A. L. and Fekete, T. (2005). Potential clindamycin resistance in clindamycinsusceptible, erythromycin-resistant Staphylococcus aureus: report of a clinical failure. Antimicrobial Agents and Chemotherapy, 49, 1222-1224.

[22] National Committee for Clinical Laboratory Standards (2004). Performance standards for antimicrobial disk susceptibility tests. 12th informational document NCCLS document M100S14 2004, PA-NCCLS. 
[23] Koppada R., Meeniga S., and Anke G (2015). Inducible Clindamycin Resistance among Staphylococcusaureus Isolated From Various Clinical Samples with Special Reference to MRSA. Scholars Journal of Applied Medical Sciences, 3(6D), 2374-2380.
[24] Baiu, S. H. and Al-Abdli, N. E. (2016). Inducible Clindamycin Resistance in Methicillin Resistant Staphylococcus aureus. American Journal of Infectious Diseases and Microbiology, 4(1), 25-27. 